\title{
Senior-Year Community Planning Studio 2013/14: Land Use and Circulation Concepts for the Broadway Corridor in Redwood City, CA
}

\author{
Zelika Pavlovich Howard \\ $M C R P$; Faculty Emeritus, \\ CRP Department, Cal Poly.
}

\author{
Shelby Messner \\ Senior, BCRP, Cal Poly.
}

The Broadway Corridor Study is a product of CRP's "learn-by-doing" pedagogy and community outreach efforts. This planning study was conducted by the senior-year Community Planning Studios under the guidance of Professor Zelika Pavlovich Howard, and in close cooperation with the Redwood City Community Development Department and the assistance from other City departments.

A $s$ the capstone courses in the undergraduate program of the City and Regional Planning Department, Community Planning Studios I and II are designed to expose students to the realties of the planning practice and to allow them to test and solidify their knowledge and understanding of the issues, the process, and the scope of planning at community scale. In these studios students are engaged in communitybased projects that offer opportunities for creative problem solving through cooperative work with community members, professional staff, advisory bodies, and government officials.

To provide an added dimension of reality to the process and the product, the projects are often conducted under a contractual agreement with the community and have a scope of work that is carefully tailored to address both the educational objectives of the course and the "client's" needs. Working under a contractual agreement with a community gives students more credibility in the eyes of the community members and often leads to a more meaningful interaction with professional staff and government officials. The community, at the same time, gives more attention to the project and is more likely to be constructively engaged in the planning process, which is crucial for developing a product that successfully addresses community challenges and aspirations.

\section{Project Overview}

Broadway Corridor Study was conducted under a contractual agreement with Redwood City, California. The purpose of the study was to assist the City in developing alternative concepts for land use and roadway use in the Broadway Corridor.

Broadway Corridor is an important development spine in Redwood City which is anchored in Downtown by the Caltrain Station and by the Stanford in Redwood City development at Second Street, in the eastern end of the City. Stanford University plans to convert the existing development on that 35 acre site to over one million square feet of new development during the next 30 years. Several projects located between these two employment centers are likely to affect Broadway Corridor over the next decade. The most prominent among them is the City's Corporation Yard located at the Woodside Road entrance into Broadway, and Redwood Plaza shopping center, directly across the streeet from the Yard. The City had recently embarked on the design of a reconstruction of the U.S. 101/Woodside Road interchange, which will also have profound impacts on the way Broadway Street functions and the entire Corridor develops in the near future.

In anticipation of the future development within and adjacent to the Broadway Corridor, the City staff directed the class to develop two alternative concepts for the roadway use of Broadway between the Caltrain Station and Second Street, and to generate ides for land use options within the one mile section of the Corridor between the eastern edge of Downtown and the western edge of the Stanford in Redwood City development.

The Study Area, encompassing approximately 100 acres, contains primarily low to medium intensity light industrial and commercial developments, with residential uses concentrated in the historic Stambaugh-Heller neighborhood in the southwest portion of the Corridor. Structures in the area are oriented toward automobile traffic, with very little attention to the needs of pedestrians and bicycles. Broadway/Woodside Road intersection, located at the center of the Corridor brings most of the traffic into the area as it feeds traffic to the Downtown as well as to the Stanford in Redwood City development.

\section{The Process}

This planning study was conducted over a period of approximately six months, during two academic quarters: Fall Quarter 2013 (late September to early December), and Winter Quarter 2014 (January to mid March). 


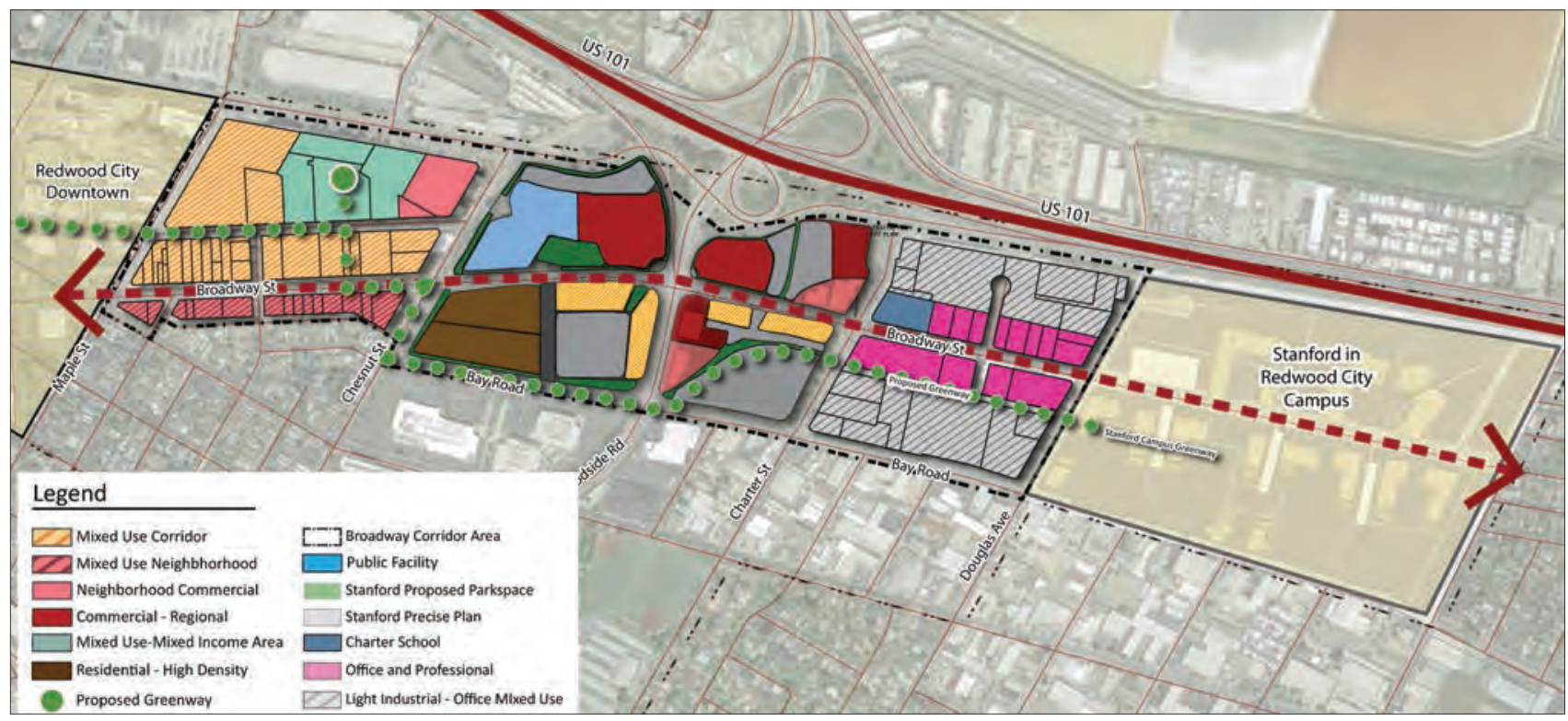

will contain mixed-use developments with emphasis on neighborhood commercial, and residential opportunities for a broad range of income groups. The scale and density of development will be compatible with the surrounding areas.

The Gateway District is located in the heart of the Corridor, at the intersection of Broadway and Woodside Road and in close proximity to the Interchange of Woodside and Highway 101. This district will provide a welcoming gateway into the City emphasizing public uses and activities that attract travelers. The plan offers two alternative concepts. The Gateway A alternative proposes enhancing and strengthening the existing land uses, incorporating new public spaces, and introducing residential development and a new public use-a Fine Arts Community Center proposed to be located at a focal point of the District to serve as a public meeting place for the entire community. The Gateway B concept offers a more intensive development option for the area involving land use changes and introduction of higher density developments. This proposal includes development strategies to support new businesses, provide affordable housing opportunities, and introduce new developments to attract visitors-a Convention Center and two hotels.

The Business District, located at the far end of the Corridor adjacent to the Stanford in Redwood City development, will be characterized by professional office development, technology, and light industrial uses that complement the Stanford in Redwood City development and the existing uses surrounding Broadway Street.

\section{Circulation Concepts}

The circulation proposal incudes recommendations for street infrastructure improvements and two alternatives for public transit system: A Streetcar System and a Bus Rapid System.
Figure 3: Concept for Broadway with Gateway B alternative.

Figure 4: Street section concept for Broadway at Beech showing the dedicated bus lanes and the median with a transit stop.

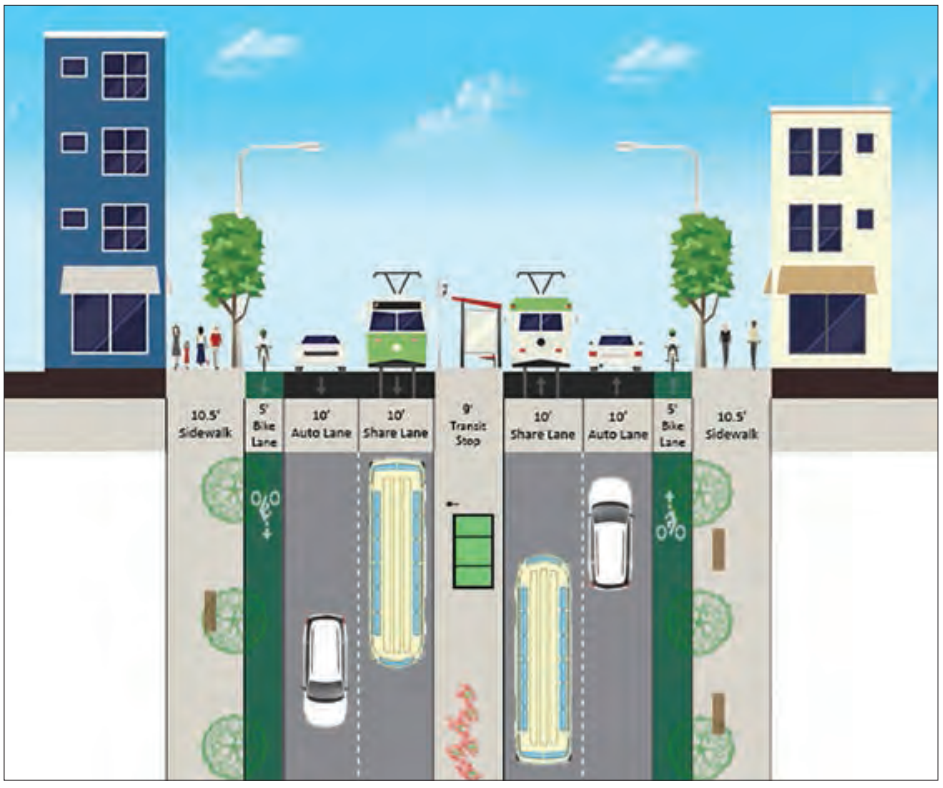

Both alternatives incorporate "complete streets" principles and treat Broadway as a "transit street", as designated by the City's General Plan. The Streetcar System proposes creating a connection between the Sequoia Caltrain Station in Downtown and the future Stanford in Redwood City development via Broadway Street, creating an approximately 3-mile long loop. The streetcar would provide a new mode of transportation along the Broadway Corridor with the possibility of expansion into surrounding areas in the future. The Bus Rapid Transit System proposal focuses on integrating a new transit system into the Corridor to enhance transit accessibility by increasing 
linkages to the existing local and regional transit systems. Both systems would enhance mobility, safety, and convenience for pedestrians and cyclists, as well as improve sidewalks and bicycle lanes to increase connectivity. Both circulation alternative proposals address route alignment, transit stations, system feasibility, and potential funding sources.

\section{Conclusion}

This project provided viable planning assistance to Redwood City and was a valuable service learning experience for the students in preparation for entering the professional planning practice. Immersion in the community planning issues helped the students understand how to apply theoretical knowledge to addressing these issues, opened their eyes to the workings of local government, and helped them understand the role of community resources and market forces in accomodating community wishes. Their work facilitated informed discussions about the issues and expectations of community members and City staff, which led to the formulation of ideas the City could use as a guide to coordinate investment and phasing of development in this important Redwood City corridor.

This project also provided background information for several senior projects that addressed potential mechanisms for implementing the project proposals including: Form Based Code for the Corridor, public space design and landscaping, and Transit Oriented Development policies. Selected senior projects were submitted to the City as supplements to the two documents prepared by the Community Planning Studio.

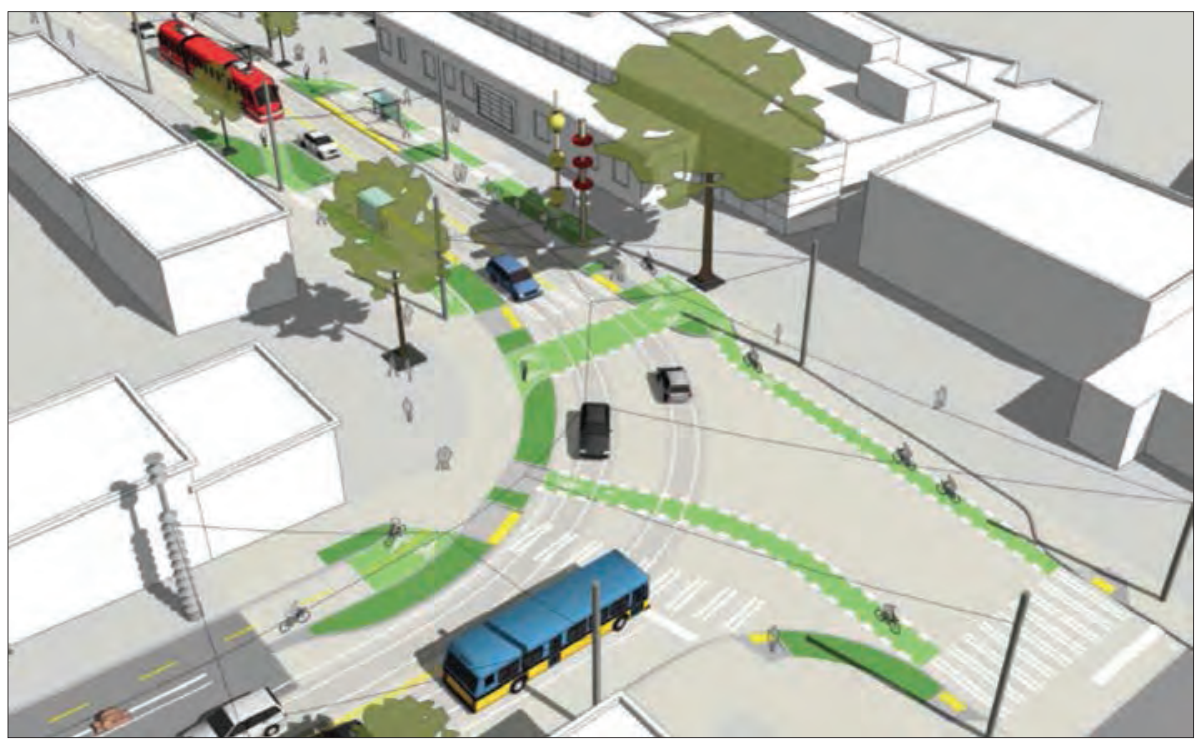

Figure 5: Concept for the intersection of Broadway Street \& Douglas Avenue, Bay Road \& Barron Avenue, and Barron Avenue \& Broadway Street.

\section{Project Participants}

Dianne Acevedo, Kyle Bell, Kelly Cheung, Jonathan Chiu, Nuri Cho, Erin Murphey, Shelby Messner, Elizabeth Day, Lisa Elgin, Malia Faasua, Fernando Herrera, Julia Hill, Shanna Hurley, David Leong, Andrew Levins, Timothy McGarvey, Peter Minegar, Sara Muse, Bailey Randall, Januar Saptono, Hillary Tung, Gregory Vine, Thomas Vogt, and Nicholas Wong. 